\title{
Young at Heart: Recent Advances in the Genetics of Congenital Heart Disease and Translational Care
}

\author{
Anna Wilsdon* \\ University of Nottingham, UK
}

Submission: February 13, 2018; Published: May 14, 2018

*Corresponding author: Anna Wilsdon, School of Life Sciences, University of Nottingham, Queen's Medical Centre, Nottingham, NG7 2RD, UK, Tel: 0115823 0314; Email: anna.wilsdon@nottingham.ac.uk

\begin{abstract}
Congenital Heart disease affects almost $1 \%$ of babies born in the UK, but few receive a genetic diagnosis. Identifying a genetic cause is important for that individual's healthcare, and that of their family. It enables accurate genetic counselling, including discussion of reproductive choices. Significant advances have been made in identifying genes that are involved in the developing heart and congenital heart disease, and research has moved away from single family studies towards genetic sequencing of large cohorts. This will bring new challenges for clinicians and researchers related to data sharing and incidental findings. In the future, we hope that new treatments can be developed based on our understanding of the complex genetic networks underlying development of the heart.
\end{abstract}

Keywords: Congenital heart disease; Genetics; Inheritance; Chromatin; Sequencing; Syndromic; Non-syndromic

\section{Introduction}

Congenital Heart Disease (CHD) encompasses a wide range of defects and affects 7-9 per 1000 births in the UK [1,2]. It has a higher mortality than many other birth defects $[1,3]$ and there is a significant genetic component to CHD. However, straight-forward mendelian inheritance is uncommon, and in the majority of cases there is a complex pattern of inheritance or a single affected family member. The developing heart relies on a specific pattern of gene expression and mutations in a number of these genes have been identified to cause CHD already. Reduced penetrance and variable expressivity suggests that there are additional factors or other genes involved too. The chance of recurrence varies between the different defects, and certain types of CHD seem to occur together more often than others [4]. Family screening has been advised for defects such as bicuspid aortic valve and hypoplastic left heart, but may not be appropriate in all cases, given the heterogeneity of the structural lesion and inheritance patterns [5]. Individuals with CHD are now living longer due to better medical and surgical care, with 95\% reaching adulthood, and most have an active life [6]. As a result, they now represent a considerable cohort of individuals requiring specialist medical care. In addition, they are more likely to survive to reproductive age and may ask about the risks of their children being affected.

\section{Aetiology}

CHD is thought to arise due to a combination of genetic and environmental factors. Contributing factors are summarised in Figure 1 [7-10] and include a number of maternal factors. Currently a genetic diagnosis can be identified in $10-20 \%$ of individuals with CHD. The history should include a three generation family tree, including neonatal demise. Additionally, exposure to teratogens, alcohol and illicit drug use may be relevant. A more generalised examination may provide useful clues to a specific diagnosis, such as limb defects or dysmorphic facies. The chance of making a diagnosis is increased if an individual has syndromic CHD (S-CHD), compared with non-syndromic CHD (NS-CHD). NSCHD is CHD in isolation, S-CHD is the combination of CHD and another congenital abnormality or neurodevelopmental disability, or both. Syndromic CHD (S-CHD) only makes up around $10 \%$ of all CHD, so the vast majority of people with CHD unfortunately do not receive a genetic diagnosis.

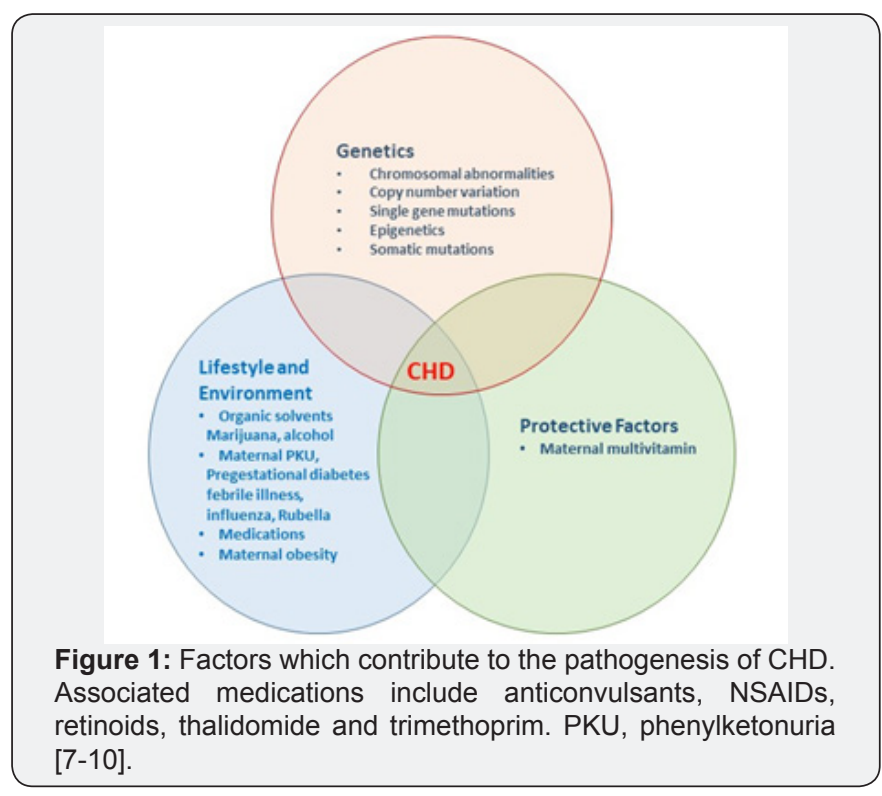




\section{Journal of Cardiology \& Cardiovascular Therapy}

Genetic causes of CHD include chromosome abnormalities, copy number variation and single gene disorders. Around $10 \%$ of CHD is thought to result from chromosomal abnormalities, which can be detected using karyotyping and array-CGH [11]. Trisomy 13, 18 and 21 commonly result in CHD. Turner Syndrome (45X) is another example. Smaller structural abnormalities such as 22q11.1 deletion syndrome and Williams Syndrome (deletion of 7q11.23) are also associated with CHD. Other examples include Wolf-Hirshorn (4p-), Cri-du-chat (5p-) and deletion of 1p36. Copy number variation (CNV) also contributes to CHD. CNVs are smaller deletions and duplications that can be detected by array-CGH, but would not be evident on a karyotype. There are now a number of recognised microdeletion and microduplication syndromes that include CHD as part of the phenotype, such as the 1q21.1 microdeletion [12]. Reduced penetrance appears to be relatively common amongst the microdeletion and duplication syndromes, which makes genetic counselling much more challenging.

Around 5\% of CHD is thought to result from single gene disorders [13]. Mutations in a number of genes causing CHD have been described and include those encoding transcription factors and cardiac structural proteins (Table 1). Epigenetic factors such as chromatin and histone remodelling, and DNA methylation are important in controlling which genes are expressed. A number of genes involved in chromatin regulation are already linked with CHD such as KMT2D, KDM6A (Kabuki Syndrome) and CHD7 (Charge Syndrome). Somatic mutations in the heart are only thought to play a small role in the pathogenesis of CHD [14].

Table 1: Examples of single gene causes of both syndromic and non-syndromic CHD and the more common CHD phenotypes seen with each.

\begin{tabular}{|c|c|}
\hline Gene & Disorder \\
\hline PTPN11 and other genes in the RAS MAPK pathway & $\begin{array}{c}\text { Noonan Syndrome and related disorders: Pulmonary valve stenosis, peripheral pulmonary } \\
\text { artery stenosis, HCM, short stature, dysmorphic facies, variable developmental delay, } \\
\text { coagulation defects, lymphatic dysplasias }\end{array}$ \\
\hline$K M T 2 D, K D M 6 A$ & $\begin{array}{l}\text { Kabuki Syndrome: CoA, ASD, VSD dysmorphic facies, poor postnatal growth, foetal finger } \\
\text { pads, joint laxity, otitis media }\end{array}$ \\
\hline CHD7 & $\begin{array}{l}\begin{array}{l}\text { Charge Syndrome: ASD, AVSD, coloboma, atresia choanae, poor growth, mental retardation, } \\
\text { genital and ear abnormalities }\end{array}\end{array}$ \\
\hline JAG1 and NOTCH2 & $\begin{array}{c}\text { Alagille Syndrome: Peripheral pulmonary artery stenosis, TOF, butterfly vertebrae, } \\
\text { posterior embryotoxon, subtle facial features, prolonged neonatal jaundice secondary to } \\
\text { intrahepatic bile duct hypoplasia }\end{array}$ \\
\hline TBX5 & $\begin{array}{l}\text { Holt Oram Syndrome: ASD, VSD, MVP, ECG abnormalities, bilateral and usually symmetrical } \\
\text { upper limb abnormalities }\end{array}$ \\
\hline DHCR7 & $\begin{array}{l}\text { Smith-Lemli-Opitz: AVSD, TAPVD, pre and postnatal growth failure, cleft palate, } 2,3 \text { toe } \\
\text { syndactyly, postaxial polydactyly, dysmorphic facies with ptosis }\end{array}$ \\
\hline NKX2.5 & ASD, TOF, VSD, HLHS \\
\hline NOTCH1 & $\begin{array}{l}\text { Aortic Valve Disease, Adams Oliver Syndrome: limb defects, congenital cutis aplasia of the } \\
\text { scalp }\end{array}$ \\
\hline GATA4 & ASD, AVSD, TOF, VSD \\
\hline MYH6 & Atrial septal defect, cardiomyopathy \\
\hline
\end{tabular}

\section{Identifying novel CHD genes}

Traditionally novel pathogenic genes were identified by studying families with multiple affected members. Subsequently, targeted sequencing of a candidate gene might be carried out in a larger cohort of individuals with the same phenotype. Both of these strategies may fail to uncover the true phenotypic spectrum associated with a particular gene and there is always a risk of missing another pathogenic mutation. It also does not provide an accurate incidence of CHD due to that specific gene and functional follow up studies are not always carried out. More recently, whole exome sequencing (WES) has been used in large cohorts of individuals with CHD to identify novel genes that cause CHD. The number of mutations identified in the CHD cohort can be compared to the number expected by chance and control populations. Mutations can be stratified by type and their predicted effect on the gene, including loss of function, gain of function, protein truncating, missense and synonymous. Analysis of the proband and parent's DNA allows us to determine if the mutation is de novo or inherited.
Studies have shown that individuals with CHD have more de novo loss of function and predicted deleterious missense mutations than expected by chance and compared to controls [15-17]. In addition, they show an increased number of mutations in genes that are highly expressed in the embryonic mouse heart which are likely to be important in the formation of the heart. De novo protein damaging mutations in these genes are thought to account for $20 \%$ of individuals with S-CHD and $2 \%$ of isolated CHD [16]. Genes involved in histone and chromatin modification appear to be especially important $[17,18]$. Novel CHD genes uncovered using this approach include CDK13, CHD4, PRKD1, RBFOX2 and FLT4. Recessive causes identified include a GDF1 founder mutation, and recessive genotypes have been seen in genes previously associated with dominant disease (MYH6) [19]. These results suggest that genetic aberrations play an important role in the pathogenesis of CHD.

These WES based studies have also provided an insight into the inheritance of CHD (Figure 2). S-CHD was postulated to be a 
result of de novo mutations, and this was confirmed by Homsy et al. [16]. However, for NS-CHD a significant excess of mutations that truncate the protein, was identified in genes inherited from healthy parents [15]. This suggests these mutations exhibit reduced penetrance and goes some way to explain the apparently sporadic nature of NS-CHD in many families.

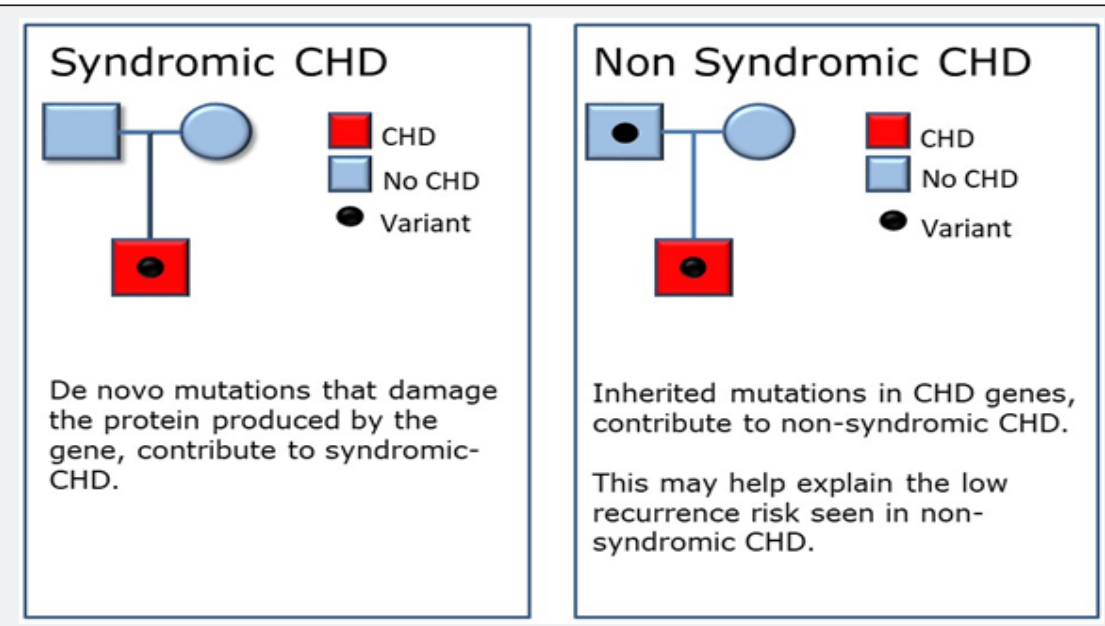

Figure 2: Comparison of the mutational profile behind syndromic and non-syndromic CHD.

\section{Translational aspects}

Since the initial description of individuals with CHD and mutations in CDK13 and CHD4, further case reports have been published $[20,21]$. The phenotype of these specific syndromes will likely continue to expand and a distinct facial gestalt for $C D K 13$ and CHD 4 has been recognised. This will hopefully mean that clinicians are able to identify affected individuals and instigate genetic testing. Describing the non-cardiac phenotypes will also guide further investigations and give information on prognosis. Both of these genes show reduced penetrance for CHD, 59\% of individuals with CDK13 mutations have CHD and 70\% of those with CHD4 mutations. The mechanism behind this is still unclear but not unexpected given that reduced penetrance is a common theme in CHD.

Making a genetic diagnosis may not alter the medical treatment offered to an individual, but it can still provide important information. Making a syndromic diagnosis may mean that additional screening of other organ systems is offered, as in Noonan Syndrome for example. The individual may wish to consider pre-conceptual counselling, genetic testing in a pregnancy, or even preimplantation genetic diagnosis. Cardiac screening can be offered to other family members in some instances, but genetic testing may offer a more definitive answer and mean that only those who are mutation positive require further investigations. In the future, we may be able to identify a genetic cause of CHD in more people and provide more tailored medical care [7-10]. Understanding the network of genes involved in CHD may open up different treatment avenues for investigation, such as the use of stem cells.

\section{Conclusion}

Although significant progress has been made in understanding the genetic contribution to CHD, there is still some way to go. A number of novel genes have been described and the different contribution of de novo and inherited variants to S-CHD and NSCHD has been identified. What has become apparent is that we will need to analyse far bigger cohorts, ideally DNA from tens of thousands of individuals [15]. Such a vast study will require collaboration between many research groups and clinicians. This brings with it the challenges of big data analysis, data sharing and confidentiality of genetic data. Research teams and clinicians should consider the possibility of incidental findings, such as a mutation in a tumour suppressor gene or carrier gene status when sequencing exomes or the whole genome. In addition to the genetic contribution, the importance of environmental and parental factors should not be neglected. Factors such as maternal obesity may become more relevant given the increasing rates of obesity worldwide. Health services should also adapt to care for the increasing numbers of adults with CHD and the specific needs they may have, including genetic counselling. Hopefully in the future, new therapies can be developed for both CHD and the failing heart based on our increasing knowledge of the genetic controls of heart development and their interaction with the environment.

\section{Acknowledgement}

A Wilsdon is a British Heart Foundation Sponsored Clinical Research Fellow FS/14/51/30879.

\section{References}

1. Hoffman JI, Kaplan S (2002) The incidence of congenital heart disease. J Am Coll Cardiol 39(12): 1890-1900.

2. Oyen N, Poulsen G, Boyd HA, Wohlfahrt J, Jensen PK, et al. (2009) Recurrence of congenital heart defects in families. Circulation 120(4): 295-301.

3. Linde D, Konings EE, Slager MA, Witsenburg M, Helbing WA, et al. (2011) Birth prevalence of congenital heart disease worldwide: a systematic review and meta-analysis. J Am Coll Cardiol 58(21): 22412247. 
4. Ellesoe SG, Workman CT, Bouvagnet P, Loffredo CA, McBride KL, et al. (2017) Familial co-occurrence of congenital heart defects follows distinct patterns. European Heart Journal 39(12): 1015-1022.

5. Perry DJ, Mullen CR, Carvajal HG, Brar AK, Eghtesady P (2017) Familial screening for left-sided congenital heart disease: What is the evidence? What is the cost? Diseases 5(4): E29.

6. Mandalenakis Z, Rosengren A, Skoglund K, Lappas G, Eriksson P, et al. (2017) Survivorship in children and young adults with congenital heart disease in Sweden. JAMA Intern Med 177(2): 224-230.

7. Jenkins KJ, Correa A, Feinstein JA, Botto L, Britt AE, et al. (2007) Noninherited risk factors and congenital cardiovascular defects: current knowledge: a scientific statement from the American Heart Association Council on cardiovascular disease in the young: Endorsed by the American Academy of pediatrics. Circulation 115(23): 2995-3014.

8. Cai GJ, Sun XX, Zhang L, Hong Q (2014) Association between maternal body mass index and congenital heart defects in offspring: a systematic review. Am J Obstet Gynecol 211(2): 91-117.

9. Block SR, Watkins SM, Salemi JL, Rutkowski R, Tanner JP, et al. (2013) Maternal pre-pregnancy body mass index and risk of selected birth defects: evidence of a dose-response relationship. Paediatr Perinat Epidemiol 27(6): 521-531.

10. Brite J, Laughon SK, Troendle J, Mills J (2014) Maternal overweight and obesity and risk of congenital heart defects in offspring. Int J Obes (Lond) 38(6): 878-882.

11. Hartman RJ, Rasmussen SA, Botto LD, Riehle CT, Martin CL, et al. (2011) The contribution of chromosomal abnormalities to congenital heart defects: a population-based study. Pediatr cardiol 32(8): 1147-1157

12. Soemedi R, Topf A, Wilson IJ, Darlay R, Rahman T, et al. (2012) Phenotype-specific effect of chromosome 1q21.1 rearrangements and GJA5 duplications in 2436 congenital heart disease patients and 6760 controls. Hum Mol Genet 21(7): 1513-1520.
13. Lalani SR, Shaw C, Wang X, Patel A, Patterson LW, et al. (2013) Rare DNA copy number variants in cardiovascular malformations with extracardiac abnormalities. Eur J Hum Genet 21(2): 173-181.

14. Manheimer KB, Richter F, Edelmann LJ, D’Souza SL, Shi L, et al. (2018) Robust identification of mosaic variants in congenital heart disease. Hum Genet 137(2): 183-193.

15. Sifrim A, Hitz MP, Wilsdon A, Breckpot J, Turki SH, et al. (2016) Distinct genetic architectures for syndromic and nonsyndromic congenital heart defects identified by exome sequencing. Nat Genet 48(9): 10601065.

16. Homsy J, Zaidi S, Shen Y, Ware JS, Samocha KE, et al. (2015) De novo mutations in congenital heart disease with neurodevelopmental and other congenital anomalies. Science 350(6265): 1262-1266.

17. Zaidi S, Choi M, Wakimoto H, Ma L, Jiang J, et al. (2013) De novo mutations in histone-modifying genes in congenital heart disease. Nature 498(7453): 220-223.

18. Glessner JT, Bick AG, Ito K, Homsy JG, Rodriguez ML, et al. (2014) Increased frequency of de novo copy number variants in congenital heart disease by integrative analysis of single nucleotide polymorphism array and exome sequence data. Circ Res 115(10): 884-896.

19. Jin SC, Homsy J, Zaidi S, Lu Q Morton S, et al. (2017) Contribution of rare inherited and de novo variants in 2,871 congenital heart disease probands. Nat genet 49(11): 1593-1601.

20. Weiss K, Terhal PA, Cohen L, Bruccoleri M, Irving M, et al. (2016) De Novo mutations in CHD4, an ATP-dependent chromatin remodeler gene, cause an intellectual disability syndrome with distinctive dysmorphisms. Am J Hum Genet 99(4): 934-941.

21. Bostwick BL, McLean S, Posey JE, Streff HE, Gripp KW, et al. (2017) Phenotypic and molecular characterisation of CDK13-related congenital heart defects, dysmorphic facial features and intellectual developmental disorders. Genome Med 9(1): 73.

Your next submission with Juniper Publishers
will reach you the below assets
- Quality Editorial service
- Swift Peer Review
- Reprints availability
- E-prints Service
- Manuscript Podcast for convenient understanding
- Global attainment for your research
- Manuscript accessibility in different formats
( Pdf, E-pub, Full Text, Audio)
- Unceasing customer service
Track the below URL for one-step submission
https://juniperpublishers.com/online-submission.php

